\title{
Quality Assurance of Three Dimensional Treatment Planning System For External Photon Beam Radiotherapy
}

\author{
Moamen M.O.M. Aly ${ }^{1}$, HaniNegm², Shimaa. A. Fouad ${ }^{1}$ \\ ${ }^{1}$ Radiotherapy and Nuclear Medicine Department, South Egypt Cancer Institute, Assiut University, Assiut, \\ Egypt. \\ ${ }^{2}$ Physics Department, Faculty of Science, Assiut University, Assiut, Egypt.
}

\begin{abstract}
:
Background: The quality assurance of $3 D$ treatment planning system (TPS)will be investigated by different things such as beam configuration, dose calculation and plane evaluation which uses dose volume histogram analyzes.

Material and method: the study was performed by XIO TPS (version 4.3.3) available at South Egypt Cancer Institute (SECI). This TPS employs two different 3D algorithms (Clarkson (CLK) and Fast Fourier Transform Convolution (CON)). Relative dose calculation (RDC) in terms of percentage depth dose (PDD) and off axis beam profiles $(O A R)$ and absolute dosecalculation $(A D C)$ in terms of dose and output factor were used and compared with the measured one using ionization chambers with water or solid phantoms in medical linear accelerator linac (Siemens Mevatron MD2).Two photon energies $6 M V$ and $15 M V$ were studied using field sizes of $10 \times 10 \mathrm{~cm} 2$ and $25 \times 25 \mathrm{~cm} 2$ for open field.

Results: The OAR and PDD are divided into regions each of these having a tolerance limit of the accuracy acceptable. The large point of deviation appeared in field size $25 \times 25 \mathrm{~cm} 2$ at energy $15 \mathrm{MV}$ in outer region $\delta 4$ of $O A R$. This region recorded the largest deviation than the others regions. In PDD curves haven't any deviation.Larger deviations were observed with CLK algorithm compared to CON algorithm. 20 points out of criteria were observed in the RDC of a large field size $25 \times 25 \mathrm{~cm} 2$, while 16 points were out of criteria in the field size $10 \times 10 \mathrm{~cm} 2$.
\end{abstract}

Conclusion: This work presents a feasibility and performance of quality assurance tasks the TPS for external photon beam.

Keywords: Quality assurance, Treatment planning system (TPS), Relative dose calculation (RDC), Absolute dose calculation $(A D C)$

\section{Introduction}

Radiotherapy treatment planning (RTP) is an important part of the radiotherapy treatment process that is usually achieved using treatment planning system (TPS). It assures that the treatmentprocess is being performed correctly and thus emphasizes important responsibility of the radiation oncology physicist[1].

Successful treatment planning relies on the evaluation plan for each individual patient based on delivering the prescribed dose to the tumor target volumes while controlling thedose to the surrounding normal tissue or organ at risk. The treatment planning process starts withpatientimmobilization in required treatment position and reference marks were used to correlate the patient coordinate to the treatment machine coordinate.Then computerized computed tomography (CT)images were acquired and other imaging modalities may be used such as magnetic resonance imaging (MRI) to facilitate the target volume delineation. Anatomy definition describescontours and surfaces structures and identifies target contours. The TPS allow choosing different beam geometry and sizes to deliver the prescribed dose. Different dose calculation algorithms are available to calculate the delivereddose from these beans. Also there are different tools to access and evaluate the dose distribution after finishing the calculations. All of these steps require assurance to verify the treatment processes.

Most TPSs have the capability to calculate and display dose distributions in absolute dose calculation (ADC) and in relative dose calculation RDC. It is extremely important to ensure that all the different ways that dose can be displayed within the TPS work correctly, and that the user understands how to interpret the results [2]. Several methods can be used to express the deviations between measurements and calculations dose. Dosimetric evaluation tests involve point, line (2D), or (3D) matrix comparisons. A voxel-by-voxel comparison is ideal for this comparison, but this approach is adequate in low dose gradient areas. In high dose gradient areas like a penumbra, the spatial deviation must also be considered. A useful tool that handles this situation is the dose/distance-to-agreement check [3], which has been further developed into the so-called $\gamma$-index [4-6]. In this way acceptance criteria can be specified as a combination of the accepted dose deviation3\%, and the accepted 
distance-to-agreement $3.0 \mathrm{~mm}$ [7]. OAR and PDD curves were divided into regions $z_{1}, z_{2}$, $z_{3}$, and $z_{4}$ each of these regions having a tolerance limit of accuracy. In ADC, comparisons were made for both SSD and SAD setups.

\section{Materials}

\section{Materials and methods}

\section{Treatment planning system(TPS)}

TPS XIO software version 4.3.3 existingat South Egypt Cancer Institute (SECI) for routine use for patient treatment planning is going to be used. This TPSutilizestwo different 3D calculation algorithms (CLK and CON). This TPS were commissioned for Siemens Mevatron linear accelerator (linac). TPS has the capability to send and receive different imaging modalities such as CT, MRI, or PET/CT that is written in DICOM [Digital Imaging and Communications in Medicine]format[7].

The CLK is a well established calculation algorithm which uses a modified sector integration method based on tissue-phantom (TPR) data generated from measured percent depth doses $[11,12]$. While, CON algorithm use account convolution [13, 15] for the transport of primary and secondary radiation inside the patient and to account for the effects of tissue heterogeneities. Both compute dose by convolved the total energy released per unit mass TERMA with Monte Carlo generated energy deposition kernels [14]. The CON speeds up its calculation by calculating dose in the frequency domain [16], while assuming kernels to be invariant with position.

\section{Medical linear accelerator (linac)}

Siemens Mevatron linear accelerator MD2 will be used in all experiments. The accelerating voltage are 6MV and $15 \mathrm{MV}$.

\section{Detectors}

Radiation detector used in this study is a gas filled ionization chamber for the relative dosimetry PDD, OAR we use two semiflex ionization chambers having nominal sensitive volume $0.125 \mathrm{~cm}^{3}$, one as sample and another as reference. One of these two ionization chambers is fixed in the remote-controlled device in the water phantom tank designed for measurements of radiation field in one, two or three dimensions. The collected ionization charges from the two ionization chambers are passed to a preamplifierbefore reaching the operator computer, which reads and draws the ratio between these two chambers. The secondary Farmer type chamber is the standard ionization chamber for absolute dose measurements in radiation therapy. The nominal sensitive volume of the chamber is $0.6 \mathrm{~cm}^{3}$. This chamber was connected to the electrometer (MULTIDOS, PTW)which measures the ion chamber collected charges and uses the IAEA TRS-398 code of practice to convert these charges into dose.

\section{Phantoms}

A phantom used in this work a water phantom (Dynascan, CMS model 3112) this phantom is a large tank $60 \times 60 \mathrm{~cm}^{2}$ in length and width and $70 \mathrm{~cm}$ in depth this is having a movable remote controlled device carrying the ionization chamber operated by a computer outside the treatment room. At ADC or test cases at specific point the acrylic slab phantom is used which is consists of 40 acrylic plates with dimensions of $40 \times 40 \mathrm{~cm}^{2}$. the phantom is designed for the rang from $70 \mathrm{KV}$ to $50 \mathrm{MV}$ photon radiation and $1 \mathrm{MEV}$ to $50 \mathrm{MEV}$ electron radiation. This acrylic slab is water density equivalent.

\section{Dosimeter System}

A dosimeter system (Dynascan, CMS Associates)Inc is a computerized control system, intended to help automatic collection of linear accelerator radiation therapy beam characteristic data it provides utilities for displaying, plotting and modifying scan data.This system consists of an operator computer with software to control the measurements in three interfaces.

\section{Calibration of the Linear Accelerator}

The Linac is calibrated for both energies to deliver $100 \mathrm{cGy}$ per 100 monitor units (MU) for field size $10 \times 10 \mathrm{~cm}^{2}$ at reference depth $\left(\mathrm{d}_{\mathrm{ref}}\right)$. The calibration is done using [2] for International code of Practice with the equation:-

$$
D_{W, Q}=\frac{M_{Q} \times N_{D, W, Q_{o}} \times k_{Q, Q_{o}}}{P D D_{r e f}}
$$

Where: $D_{W, Q}$ is the absorbed dose to water at the depth of dose maximum ( $\mathrm{d}_{\max }$ unit: Gy/MU), $M_{\mathrm{Q}}$ is ratio of electrometer reading and monitor unit (charge/monitor unit, unit: C/MU or rdg/MU) corrected for air temperature and pressure $\left(\mathrm{k}_{\mathrm{T}, \mathrm{P}}\right)$, ion recombination $\left(\mathrm{k}_{\mathrm{S}}\right)$, polarity effects $\left(\mathrm{k}_{\mathrm{pol}}\right)$, and electrometer calibration 
$\left(\mathrm{k}_{\text {elec }}\right), N_{D, W, Q o}$ is absorbed dose to water calibration factor for the ionization chamber (the ionization chamber correction factor), $\mathrm{K}_{\mathrm{Q}, \mathrm{Qo}}$ is the beam quality correction factor which depends on radiation energyand, $\mathrm{PDD}_{\text {ref }}$ is percentage depth dose at reference depth.

\section{Methods}

\section{Relative dose calculation (RDC)}

RDC which means OARand PDD agree the measurements in linac and compared to the calculated in TPS. We measured two field size $10 \times 10 \mathrm{~cm}^{2}$ and $25 \times 25 \mathrm{~cm}^{2}$ for two energies $6 \mathrm{MV}$ and $15 \mathrm{MV}$ at five depths $\left(\mathrm{d}_{\max }, 5,10,15\right.$ and 20$) \mathrm{cm}$ where $\mathrm{d}_{\max }$ for the $6 \mathrm{MV}=1.5 \mathrm{cmand}$ for $15 \mathrm{MV}=3 \mathrm{cmplottedOAR}$ and PDD curves for measured dose and calculated dose by using CLK and CON.

In OARs curves plot the profile curves then calculated the mean deviation (MD) and the standard deviation

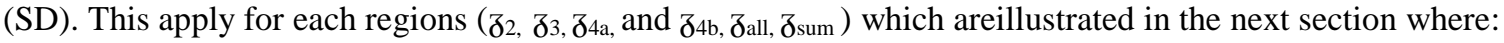

$$
M D=100 \% \times\left(D_{c a l}-D_{m e s}\right) / D_{m e s}[2]
$$

In PDD curves after plotted curves calculated the mean deviation (MD), the standard deviation (SD) for each region $\left(\delta_{1}, z_{2}\right)$ only. By using equation [2] where:

$$
P D D=\operatorname{Dose}_{(d)} / \operatorname{Dose}_{(d m a x)} \times 100 \%[3]
$$

Where $d$ is the depth of interest and $d_{\max }$ is the depth of maximum dose (reference depth).By considering the measured dose it is the reference dose then can be calculated MD andSD of all of OAR and PDD regions for CLK and CON by using the equation:

$\mathrm{D}_{\text {call }}$ : is the calculated dose by using CLK orCON.

$\mathrm{D}_{\text {mes }}$ : is the measured reference data.

\section{Tolerances limits for photon beam dose calculations}

Different acceptance criteria can, however, be formulated depending on the position in the beam. Figures (1) show the various regions that can be defined in a photon beam [3]. Different tolerances $\square$ are proposed for the various regions in a photon beam as shown in figure (1).

\section{Absolute Dose Calculation ADC}

ADC means calculated the doses at a specific point after normalized dose in TPS at $100 \mathrm{cGy}$ then TPS calculatemonitor unit under certain conditionby using the same conditionscalculated the dose measurements in (linac)measured the dose rate then calculated the difference between calculated doses in TPS and measured doses in (linac).In this section of measurements in a linac we use a solid slab water proof phantom one of ionization chamber was used havingan internal volume $0.6 \mathrm{~cm}^{3}$ for the two energy 6MV and 15MVby putting the ionization chamber at a depth of slaps of the phantoms $1.5 \mathrm{~cm}$ for energy $6 \mathrm{MV}$ and putting the chamber at depth of slaps $3 \mathrm{~cm}$ this for energy $15 \mathrm{MV}$. We measured five of field sizes $4 \times 4 \mathrm{~cm}^{2}, 10 \times 10 \mathrm{~cm}^{2}, 20 \times 20 \mathrm{~cm}^{2}, 17 \times 7 \mathrm{~cm}^{2}$ and $12 \times 19 \mathrm{~cm}^{2}$ using SSD and SAD techniques at $d_{\max }$ for the two energy. Each of these steps we agreed with and without a tray factor but $15 \mathrm{MV}$ calculated PDD at SSD 100 and monitor unit where,

$$
M U=G D \times 100 /(O F \times P D D \times T F)
$$

And for SAD used tissue phantom ratio $(T P R)$ instead of $P D D$

$$
M U=\operatorname{dose} /(T P R \times 0 \mathrm{~F} \times T F)
$$

Where, OFis the output factor.This factor differs for each energy and for each field size.

and by using triangle cornel block $0.5 \times 0.5 \mathrm{~cm}^{2}$ in field $4 \times 4 \mathrm{~cm}^{2}, 1.25 \times 1.25 \mathrm{~cm}^{2}$ in field size $10 \times 10 \mathrm{~cm}^{2}$, $2.5 \times 2.5 \mathrm{~cm}^{2}$ in field size $20 \times 20 \mathrm{~cm}^{2}, 2.13 \times 0.88 \mathrm{~cm}^{2}$ in a field size $17 \times 7 \mathrm{~cm}^{2}, 1.5 \times 2.4 \mathrm{~cm}^{2}$ in a field size $12 \times 19 \mathrm{~cm}^{2}$ all block measurements having a tray factor .953 for energy of voltage $6 \mathrm{MV}$ and .966 for energy of voltage $15 \mathrm{MV}$

\section{OARs forfield size $10 \times 10 \mathrm{~cm}^{2}$ and energy $6 \mathrm{MV}$}

\section{Results and Discussions}

Table 2 represented MD and SD of difference between measured and calculated OAR at different depths using CLK and CONs for $6 \mathrm{MV}$, for open field size $10 \times 10 \mathrm{~cm}^{2} . \gamma_{2}, z_{3}, z_{4 a}$, and $z_{4 \mathrm{~b}}$ represent different regions on the OAR curve, and the numbers between the parakeets represents the accepted limit.

The high light value in table 2 represented the unaccepted tolerance limit values. 
Quality Assurance of Three Dimensional Treatment Planning System For External Photon ...

\section{OARs for field size $10 \times 10 \mathrm{~cm}^{2}$ and energy $15 \mathrm{MV}$}

Table 3 illustrated that the MD and SD of difference between measured and calculated dose profiles at different depths using CLK and CONs for $15 \mathrm{MV}$, for open field size $10 \times 10 \mathrm{~cm}^{2} . z_{2}, z_{3}, z_{4 a}$, and $z_{4 b}$ represent different regions on the dose OAR, and the numbers between the parakeets represents the accepted limit.

\section{OARs field size $25 \times 25 \mathrm{~cm}^{2}$ for energy $6 \mathrm{MV}$}

Table 4 represented that the MD and SDof difference between measured and calculated OAR at different depths using CLK and CONs for $6 \mathrm{MV}$, for open field size $25 \times 25 \mathrm{~cm}^{2} . \gamma_{2}, z_{3}, \gamma_{4 a}$, and $z_{4 b}$ represent different regions on the OAR curve, and the numbers between the parakeets represents the accepted limit.

\section{OARs field size $25 \times 25 \mathrm{~cm}^{2}$ for energy $15 \mathrm{MV}$}

Table 5represented that the MD and SD of difference between measured and calculated OAR at different depths using CLK and CONs for $15 \mathrm{MV}$, for open field size $25 \times 25 \mathrm{~cm}^{2} . z_{2}, z_{3}$, $z_{4 a}$, and $z_{4 b}$ represent different regions on the OAR curve, and the numbers between the parakeets represents the accepted limit.From tables $2,3,4,5$ of the OAR it is seen that the unaccepted tolerance limited values or the values out of criteria for CLK is 27 points. Whilethe unaccepted values of CON it is 9 points. This means that the CON is better than the CLK this is matched with[17] where they observed that the larger of deviations in simpler algorithm like CLK. The inaccuracy of the CLK also illustrated in [10] when study the CLK and CON in different regions in human body they observed that the CLK for the chest wall. The CLK neglected the missing scatter radiation and hence, did not predict enough monitor unit than the accuracy of other algorithms CON were acceptable of accuracy so, they concludes that the CLK calculated monitor units are suitable for a simple situations geometry, but warns should be used when using monitor unit calculations for a complex geometry.

The values out of criteria in field size $25 \times 25 \mathrm{~cm}^{2}$ in all study cases is 20 values while the values out of criteria in field size $10 \times 10 \mathrm{~cm}^{2}$ it is 15 values this means that field size $10 \times 10 \mathrm{~cm}^{2}$ is much suitable field in our study and in a lot of other studies to conceded field size $10 \times 10 \mathrm{~cm}^{2}$ the ideal field size also IAEA report 430 represented it the reference field size for The calibration is done using IAEA TRS-398. This result it is matched with [18] when they study large, square open fields $25 \times 25 \mathrm{~cm}^{2}$, calculations overestimated measurements in the tails, because the parameter that described lost scatter from the head was also modified so that monitor unit calculations would closely match clinical data. Inaccuracies in modeling scatter were also observed in the effect of modifiers or blocks on the accuracy of monitor unit calculations. A possible curative to the extra focal radiation problem is to use a dual-source photon beam model. When they study a small square open fields $5 \times 5 \mathrm{~cm}^{2}$, the calculated shoulders and tails underestimated the measured data. The underestimation resulted because parameters that described the finite source size and lot of scatter will stray from the head had to be modified so that monitor unit calculations would closely match clinical data or measured data, thus compromising the accuracy of calculations in the shoulders and tails[19,20].

The values out of criteria in $6 \mathrm{MV}$ is 14 while the values out of criteria at $15 \mathrm{MV}$ is 21 values, when seeing AAPM 23 we found that the Dose deviations greater than 3\% were observed for 51 of 532 points [in the $4 \mathrm{MV}$ case] and for 124 of 586 points [in the $18 \mathrm{MV}$ case]. This observation more matched with [17] they observed thatlarger deviations were observed for the higher beam energy [21]. Doses inside the bone equivalent material were underestimated by up to $7 \%$ for both $6 \mathrm{MV}$ and $15 \mathrm{MV}$ beams for both algorithm types [22].

The values out of criteria at energy $6 \mathrm{MV}$ it is little than the values out of criteria at energy $15 \mathrm{MV}$ this is because of the energy $15 \mathrm{MV}$ it is more penetrating than that the energy $6 \mathrm{MV}$, hence the energy $6 \mathrm{MV} \mathrm{d}_{\max }$ or the maximum depth dose in energy $6 \mathrm{MV}$ it is $1.6 \mathrm{~cm}$ shallowest than that the $\mathrm{d}_{\max }$ of energy $15 \mathrm{MV}$ equal $3 \mathrm{~cm}$, acceptable uniformity of dose, that is, within $\pm 5 \%$, is achievable with cobalt 60 or 4 to $6 \mathrm{MV}$ beams for thicknesses of about $15 \mathrm{~cm}$ or less head, neck, breast, and extremities. However, for thicknesses of $20 \mathrm{~cm}$ or greater thorax, parotid, abdomen, and pelvis, $10 \mathrm{MV}$ or higher energies must be used to spare the normal subcutaneous tissues [5].So, the small energy 6MV affected by the phenomena of the surface tension than the energy 15MV this is making it non uniformity of distribution from the biggest energy 15MV.

\section{PDD for field size $10 \times 10 \mathrm{~cm}^{2}$}

Table 7 represented that the MD andSDof difference between measured and calculated PDD using CLK and CON for 6MV, $15 \mathrm{MV}$ for open field size $10 \times 10 \mathrm{~cm}^{2}, 25 \times 25 \mathrm{~cm}^{2} . z_{1}, z_{2}$ and $z_{\text {sum, }}$ represent different regions on the PDD and OAR, and the numbers between the parakeets represents the accepted limit.

From table 7 of depth dose we can observe that no values out of criteria in the buildup regions this is matched with [10] when they found that only 6 values out of 4138 values exceeding the TG-53 criteria for the buildup region all the 6 values in the multi leave collimator(MLC) shaped field test case.They found that $99 \%$ of points in the buildup regions, but in our study we observed that $100 \%$ of points in buildup regions ${ }_{2}$, because they study in MLC shaped field but, we not study in this case. 
when comparing[18] with the resultant concludes that $99 \%$ of points in the buildup region, $90 \%$ of points in the inner region while in our study $100 \%$ for the buildup and inner regions, $88 \%$ of points in the outer region in our study $72.5 \%$, and $93 \%$ of points in the penumbra but, in our study $82.5 \%$.

\section{Absolute doses \\ SSD technique}

Table 8represented that the MD of ADC for difference between measured and calculated doses using CLK, CON in open field sizes $4 \times 4 \mathrm{~cm}^{2}, 10 \times 10 \mathrm{~cm}^{2}, 20 \times 20 \mathrm{~cm}^{2}, 17 \times 7 \mathrm{~cm}^{2}, 12 \times 19 \mathrm{~cm}^{2}$ in SSD technique with using block and without using block (with and without a Tray Factor) for two energy 6MV, $15 \mathrm{MV}$ with tolerance limit $2 \%[9]$

\section{SAD technique}

Table 9represented that the MD of ADC for difference between measured dose and calculated dose using CLK, CON in open field sizes $4 \times 4 \mathrm{~cm}^{2}, 10 \times 10 \mathrm{~cm}^{2}, 20 \times 20 \mathrm{~cm}^{2}, 17 \times 7 \mathrm{~cm}^{2}, 12 \times 19 \mathrm{~cm}^{2}$ in SAD technique with using block and without using block (with and without a Tray Factor) for two energy 6MV, 15MV with tolerance limit $2 \%$ [9]

In the absolute section of study, we observed thata large of deviation in the SAD technique than the SSD technique this is because of the influence of SSD variation on TPS this is matched with [9] they found that as SSD decreased, absolute deviation in SSD were found to increase for all field sizes, being within the acceptability tolerance level.The values out of criteria are so large whether SSD or SAD technique. In ESTRO [3]the acceptance level for the accuracy of dose calculations of a TPS should be around 2\%. This value can be used for areas where the absorbed dose is rather homogenous, e.g., inside the central part of a beam. When comparing our results with [9]the mean deviation of errors of the order of $\pm 2 \%$ to reach to the maximum deviation of $\pm 12.2 \%$ at only a small field size which be study it $4 \times 4 \mathrm{~cm}^{2}$ in[9] we found that they showed a mean deviation of the order of $\pm 3.5 \%$, reached a maximum of $\pm 11.5 \%$ for small field size $5 \times 5 \mathrm{~cm}^{2}$ becausefield size $4 \times 4 \mathrm{~cm}^{2}$ is smallerthan the field size $5 \times 5 \mathrm{~cm}^{2}$ in[9] so, the rate of deviations exceeded in $4 \times 4 \mathrm{~cm}^{2}$ than $5 \times 5 \mathrm{~cm}^{2}$. In[18]when they study some small square open fields $5 \times 5 \mathrm{~cm}^{2}$, the calculated shoulders and tails underestimated the measured data. The underestimation resulted because parameters that described the finite source size and lot of scatter will stray from the head had to be modified so that monitor unit calculations would closely match clinical data or measured data, thus compromising the accuracy of calculations in the shoulders and tails [19, 20]. From $[18,9]$ the rate of deviations should be increased when using a smaller field size than $5 \times 5 \mathrm{~cm}^{2}$.

In[18] which dependent on the criteria of AAPM 53[1] so, don't meeting in the criteria acceptability of TG-53 specifically when modifiers or blocks were applied to the beam. The discrepancies in monitor unites for $18 \mathrm{MV} 5 \times 5 \mathrm{~cm}^{2}$ and $18 \mathrm{MV} 25 \times 25 \mathrm{~cm}^{2}$ beams also didn't met the TG-53 criterion of $\pm 0.5 \%$.however, these criteria don't include the errors in determining the absolute dose under stander calibration conditions, in their tolerance figures for the absolute dose at the normalization point. The criteria don't provide for errors in determining the total scatter factor in their estimate for acceptable agreement also, the errors in monitor units for rectangular fields exceeded the TG-53 tolerance of $\pm 0.5 \%$.

\section{Acknowledgement}

I would like to express my profound gratitude and sincere appreciation to Prof. Dr. Abdel-Hady ElKamel, Physics Department, Assiut University, for his supervision, constructive guidance, critical comments, continuous help and great efforts throughout this work.

\section{References}

[1]. Fraass. B, K. Doppke, M. Hunt, G. Kutcher, G. Starkschall, R. Stern, and J V. Dyke AAPM radiation therapy commit Task Group 53: "Quality assurance for clinical radiotherapy treatment planning" Med.Phys. Vol: 25PP 1773, (1998).

[2]. IAEA_ Technical reports series no.430 "commissioning and quality assurance computerized planning systems for radiation treatment of cancer" PP 158, (2004).

[3]. Mijnhee. B, A. Olszewska., C. Fiorino., G. Hartmann., T. Knöös., J.C. Rosenwald and H. Welleweerd "Quality assurance of treatment planning systems practical examples of non-IMRT photon beams." First edition by ESTRO. (2004).

[4]. Harms W.B, D.A. Low., J.W. Wong and J.A. Purdy"A software tool for the quantitative evaluation of 3D dose calculation algorithms". Med. Phys.vol: 25, PP(1830-1836), (1998).

[5]. Depuydt. T,A. Van Esch and D.P.Huyskens "A quantitative evaluation of IMRT dose distributions: refinement and clinical assessment of the gamma evaluation. Radiother". Oncol.vol:62, PP(309-319), (2002).

[6]. Low. D.A and J.F. Dempsey "Evaluation of the gamma dose distribution comparison method". Med. Phys. vol: 30, PP(24552464),(2003).

[7]. Bakai. A, M. Alber and F. Nüsslin "A revision of the $\gamma$-evaluation concept for the comparison of dose distributions". Phys. Med. Biol. vol: 48, PP(3543-3553), (2003).

[8]. Venselaara. J, H. Welleweerdb and B. Mijnheer "Tolerances for the accuracy of photon beam dose calculations of treatment planning systems" Red\& Oncol. Vol:60, PP(191-201), (2001).

[9]. Sandilos. P, S. Seferlis, C. Antypas, P. Karaiskos, C. Dardoufas and L. Vlahos "Technical note: evaluation of dosimetric performance in a commercial 3D treatment planning system" Brit Jour. vol: 78, (2005). 
[10]. Butts. J .R, and A. E. Foster "Comparison of commercially available three-dimensional treatment planning algorithms for monitor unit calculations in the presence heterogeneities Indiana", CLI Med. Phys, vol: 2, PP 1, (2001).

[11]. Khan. F. M, "The physics of radiation therapy", 3rd edition, Williams and Wilkins, Baltimore, Landon, CH 9, PP 175, (2003).

[12]. Louis. St, MO Computerized Medical Systems, "Dose Calculation-Clarkson, Calculation Physics and Clinical Applications Manual"Vol. 1, CH. 4, PP. 1-123, (1999).

[13]. Ahnesjo. A, "Collapsed Cone convolution of radiant energy for photon dose calculations in heterogeneous media", Med. Phys. vol: 16, PP (577-592), (1989).

[14]. Mackie. T. R, A. F. Bielajew, D. W. Rogers, and J. J. Battista, "Generation of photon energy deposition kerna using the EGS Monte Carlo Code " Phys. Med. Biol. vol: 33, PP(1-20), (1998).

[15]. Boyer. A. L, Y. Zhu, L. Wang, and P. Francois, "Fast Fourier transform convolution calculations of x-ray isodose distributions in inhomogeneous media" Med. Phys. vol: 16, PP (248-253), (1989).

[16]. Sontag. M. R and J. R. Cunningham, "Corrections to absorbed dose calculations for tissue in homogeneities" Med. Phys. vol: 4, PP (431-436), (1977).

[17]. Rutonjski. L, B. Petrovic, M. Baucal, M. Teodorovic, O. Cudic, E. Gershkevitsh and J. Izewska. "Dosimetric verification of radiotherapy treatment planning systems in Serbia" Rad. Oncol, vol: 7, PP 155, (2012).

[18]. Gifford.K. A, D. S. Followill, H. H Liu and G. Starkschall "Verification of the accuracy of a photon dose-calculation algorithm", Clin. Med. Phys, vol: 3, PP 1, (2002).

[19]. Liu. H. H, T. R. Mackie, and E. C. McCullough, "A dual source photon beam model used in convolution dose calculations for clinical megavoltage x-ray beams" Med. Phys. vol: 24, PP (1960-1974), (1997).

[20]. Starkschall. G, R. E. Steadham, N. H. Wells, L. O’Neill, L. A. Miller, and I. I. Rosen, "On the need for monitor unit calculations as part of a beam commissioning methodology for a radiation treatment planning system" Clin. Med. Phys, vol: 1, PP (86-94), (2000).

[21]. Alam. R, G. S. Ibbott, R. Pourang, R .Nath Application of AAPM Radiation Therapy Committee Task Group 23 test package for "comparison of two treatment planning systems for photon external beam radiotherapy" Med. Phys vol: 24: PP (2043-2054), (1997).

[22]. Carrasco. P, N. Jornet and MA. Duch "Comparison of dose calculation algorithms in slab phantoms with cortical bone equivalent heterogeneities" Med Phys, vol: 34, PP (3323-3333), (2007).

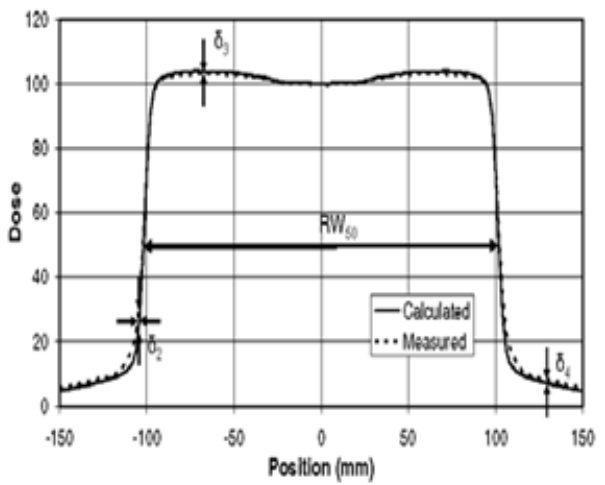

(a)

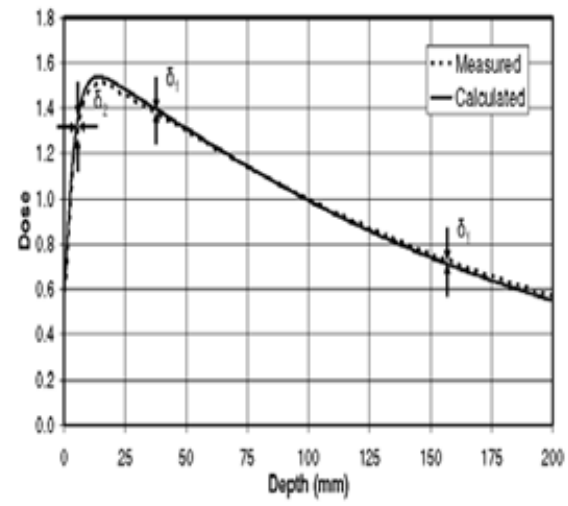

(b)

Figure 1 illustrated different regions where the criteria $\delta_{1}-\delta_{4}$ can be applied to compare calculated and measured values of a beam profile (A) [3] and a depth dose curves (B) [3]. Data is normalized at the central beam axis

Table 1: Tolerance $\delta$, given as the confidence limit, for the dose deviation, for the various regions in a photon beam [4].

\begin{tabular}{|c|c|c|}
\hline & Region & $\begin{array}{l}\text { Homogeneous } \\
\text { simple geometry }\end{array}$ \\
\hline${ }_{1} \delta$ & $\begin{array}{r}\text { Central beam axis data - high dose, low } \\
\text { dose gradient }\end{array}$ & $2 \%$ \\
\hline $2 \delta$ & $\begin{array}{r}\text { Build-up region of central axis beam, } \\
\text { penumbra region of the profiles - high } \\
\text { dose, high dose gradient. }\end{array}$ & $10 \%$ \\
\hline 30 & $\begin{array}{r}\text { Outside central beam axis region high } \\
\text { dose, low dose gradient }\end{array}$ & $3 \%$ \\
\hline $4 \delta$ & $\begin{array}{l}\text { Outside beam edges - low dose and low } \\
\text { dose gradient divided this region into } \\
\text { two part } \boldsymbol{\delta}_{4 \mathrm{a}}, \boldsymbol{\delta}_{4 \mathrm{~b}} \text { where } \boldsymbol{\delta}_{4 \mathrm{a}} \text { before the } \\
\text { central axis and } \boldsymbol{\delta}_{4 \mathrm{~b}} \text { after the central axis } \\
\text { in OAR curve. }\end{array}$ & $30 \%$ \\
\hline allo & It is all a profile data points & $3 \%$ \\
\hline $\operatorname{sum} \delta$ & $\begin{array}{r}\text { It is a summation } \boldsymbol{\delta}_{3} \text { in all profile depths } \\
\text { which can be measured }\end{array}$ & $3 \%$ \\
\hline
\end{tabular}


Quality Assurance of Three Dimensional Treatment Planning System For External Photon ...

Table 2: MD and SD of difference between measured and calculated dose profiles at different depths using CLK and CONs for $6 \mathrm{MV}$, for open field size $10 \times 10 \mathrm{~cm} 2 . z^{2}, z^{3}, z^{4 a}$, and $z^{4 b}$ represent different regions on the OAR curve, and the numbers between the parakeets represents the accepted limit.

\begin{tabular}{|c|c|c|c|c|c|c|c|c|c|c|c|}
\hline \multirow{2}{*}{ Depth } & & \multicolumn{2}{|c|}{$\delta^{2}[10 \%]$} & \multicolumn{2}{|c|}{$\delta^{3}[3 \%]$} & \multicolumn{2}{|c|}{$\bar{\delta}^{4 a}[30 \%]$} & \multicolumn{2}{|c|}{$\bar{\delta}^{4 \mathrm{~b}}[30 \%]$} & \multicolumn{2}{|c|}{$\bar{\delta}^{\text {all }}[3 \%$ ] } \\
\hline & & CLK & CON & CLK & CON & CLK & $\mathrm{CON}$ & CLK & CON & CLK & $\mathrm{CON}$ \\
\hline \multirow{2}{*}{1.5} & MD & 8.9 & 6.7 & 1.4 & 1.1 & -48.9 & -27 & -43.9 & -20.3 & -4.2 & -0.9 \\
\hline & SD & 9.8 & 10 & 3.4 & 2.9 & 9.1 & 2.5 & 11.8 & 3.4 & 21.9 & 13.9 \\
\hline \multirow{2}{*}{5} & MD & 16.1 & 11.2 & 2.1 & 0.1 & -37.7 & -17 & -33.9 & -12 & -0.9 & 0.3 \\
\hline & SD & 12.6 & 11.5 & 1.5 & 0.8 & 11.5 & 3.4 & 11.5 & 2.5 & 16.4 & 9 \\
\hline \multirow{2}{*}{10} & MD & -2.1 & -3.9 & 0.6 & -0.4 & -29.2 & -16.8 & -23.4 & -10.2 & -0.1 & 0.1 \\
\hline & SD & 1.4 & 1.3 & 1.3 & 1 & 15.8 & 5.9 & 14.3 & 4.7 & 13.1 & 9.2 \\
\hline \multirow{2}{*}{15} & MD & -0.6 & -1.9 & 0.1 & -1.4 & -20.8 & -14.8 & -15.6 & -9.3 & 0.6 & -0.6 \\
\hline & SD & 0.6 & 0.4 & 0.9 & 0.6 & 10.8 & 5.4 & 11.4 & 5.7 & 8.8 & 6.2 \\
\hline \multirow{2}{*}{20} & MD & -1.9 & -4.1 & -0.1 & -2.4 & -10 & -15.1 & 2.3 & -3.6 & 1.8 & -1.2 \\
\hline & SD & 2.5 & 1.6 & 1.1 & 0.7 & 6.1 & 3.4 & 10.7 & 7.4 & 8.4 & 7.4 \\
\hline
\end{tabular}

Table 3: MD and SD of difference between measured and calculated OAR at different depths using CLK and CON for $15 \mathrm{MV}$, for open field size $10 \times 10 \mathrm{~cm}^{2} \cdot z_{2}, \zeta_{3}, \zeta_{4 a}$, and $\zeta_{4 \mathrm{~b}}$ represent different regions on the OAR curve, and the numbers between the parakeets represents the accepted limit.

\begin{tabular}{|c|c|c|c|c|c|c|c|c|c|c|c|}
\hline \multirow{2}{*}{ Depth } & & \multicolumn{2}{|c|}{$\delta^{2}[10 \%]$} & \multicolumn{2}{|c|}{$\delta^{3}[3 \%]$} & \multicolumn{2}{|c|}{$\bar{\delta}^{4 a}[30 \%]$} & \multicolumn{2}{|c|}{$\bar{\delta}^{4 \mathrm{~b}}[30 \%]$} & \multicolumn{2}{|c|}{$\bar{\delta}^{\text {all }}[3 \%]$} \\
\hline & & CLK & CON & CLK & CON & CLK & CON & CLK & CON & CLK & CON \\
\hline \multirow{2}{*}{3} & MD & 0.7 & -5.4 & 1.2 & 0.6 & -42.6 & -17.5 & -36.6 & -9.1 & -5.4 & -7.6 \\
\hline & SD & 5.1 & 1.2 & 2.2 & 1.9 & 9.3 & 3.1 & 11.2 & 2.6 & 19 & 20.3 \\
\hline \multirow{2}{*}{5} & MD & 11.6 & 5 & 1.8 & 0.7 & -43.6 & -8.5 & -43.2 & -7.9 & -0.8 & -2.4 \\
\hline & SD & 9.7 & 3.8 & 1.5 & 0.6 & 6.2 & 3.1 & 7 & 3.8 & 17.2 & 17.1 \\
\hline \multirow{2}{*}{10} & MD & -2.4 & -4.1 & 1.4 & 0.9 & -33.3 & -13.2 & -42.7 & -2.3 & -2.7 & -2.1 \\
\hline & SD & 2.6 & 3.5 & 1.4 & 0.8 & 9.3 & 1.6 & 12.7 & 2 & 12.5 & 9.8 \\
\hline \multirow{2}{*}{15} & MD & 1 & 0.7 & 1.4 & 0.7 & -17.8 & -11.1 & -14 & -7 & -1.8 & -0.8 \\
\hline & SD & 1.7 & 1 & 1.2 & 0.6 & 12.3 & 1.7 & 12.9 & 2 & 10.4 & 4.2 \\
\hline \multirow{2}{*}{20} & MD & -0.1 & -0.7 & 1.6 & 0.3 & -6.3 & 14.1 & 9.8 & 0.6 & -2.4 & -2.7 \\
\hline & SD & 3.3 & 2.2 & 1.1 & 0.7 & 8.8 & 1.7 & 11.6 & 3.1 & 8.2 & 4.8 \\
\hline
\end{tabular}


Quality Assurance of Three Dimensional Treatment Planning System For External Photon ...

Table 4: MD and SD of difference between measured and calculated dose profiles at different depths using CLK and CONs for $6 \mathrm{MV}$, for open field size $25 \times 25 \mathrm{~cm}^{2} \cdot z_{2}, z_{3}, z_{4 a}$, and $z_{4 b}$ represent different regions on the OAR curve, and the numbers between the parakeets represents the accepted limit.

\begin{tabular}{|c|c|c|c|c|c|c|c|c|c|c|c|}
\hline \multirow{2}{*}{ Depth } & & \multicolumn{2}{|c|}{$\delta^{2}[10 \%]$} & \multicolumn{2}{|c|}{$\bar{\delta}^{3}[3 \%]$} & \multicolumn{2}{|c|}{$\bar{\delta}^{4 a}[30 \%]$} & \multicolumn{2}{|c|}{$\bar{\delta}^{4 \mathrm{~b}}[30 \%]$} & \multicolumn{2}{|c|}{$\bar{\delta}_{\text {all }}[3 \%]$} \\
\hline & & CLK & $\mathrm{CON}$ & CLK & CON & CLK & $\mathrm{CON}$ & CLK & $\mathrm{CON}$ & CLK & $\mathrm{CON}$ \\
\hline \multirow{2}{*}{1.5} & MD & 13.9 & 12 & 1.1 & 0.3 & -62.5 & -14.4 & -61.5 & -12.3 & -4.6 & 0.5 \\
\hline & SD & 5.7 & 9.7 & 1.9 & 1.1 & 8.1 & 11.8 & 8.2 & 12.1 & 20.9 & 8.5 \\
\hline \multirow{2}{*}{5} & MD & 14.6 & 6.3 & 2.1 & 0.4 & -50.1 & -15.1 & -48.3 & -12.1 & -0.4 & 0.6 \\
\hline & SD & 8.2 & 6.1 & 1.7 & 0.4 & 2.1 & 9.5 & 2.5 & 9.6 & 14.8 & 6.4 \\
\hline \multirow{2}{*}{10} & MD & 5 & -0.3 & 0.3 & -0.2 & -22.5 & -13.6 & -17 & -7.5 & 0.8 & 0.1 \\
\hline & SD & 1.3 & 1 & 1.8 & 0.3 & 17.1 & 9.9 & 19.8 & 12.1 & 8.6 & 5.5 \\
\hline \multirow{2}{*}{15} & MD & 5.1 & -0.7 & -0.5 & -1 & 11.8 & -1.2 & 18.7 & 4.8 & 1.3 & -0.6 \\
\hline & SD & 0.4 & 0.2 & 1.9 & 0.4 & 10.9 & 13.6 & 8.8 & 12.1 & 5.2 & 2.8 \\
\hline \multirow{2}{*}{20} & MD & 4.5 & -2.3 & -0.5 & -2 & 8.6 & -18.8 & 26.6 & -5.1 & 0.8 & 2.3 \\
\hline & SD & 0.5 & 0.3 & 1.8 & 0.4 & 3.1 & 9.7 & 1.6 & 15.2 & 4.3 & 2.6 \\
\hline
\end{tabular}

Table 5: MD and SD of difference between measured and calculated OAR at different depths using CLK and CONs for $15 \mathrm{MV}$, for open field size $25 \times 25 \mathrm{~cm} 2 . z^{2}, z^{3}, z^{4 a}$, and $z^{4 b}$ represent different regions on OAR curve, and the numbers between the parakeets represents the accepted limit.

\begin{tabular}{|c|c|c|c|c|c|c|c|c|c|c|c|}
\hline \multirow{2}{*}{ Depth } & & \multicolumn{2}{|c|}{$\delta^{2}[10 \%]$} & \multicolumn{2}{|c|}{$\bar{\delta}^{3}[3 \%]$} & \multicolumn{2}{|c|}{$\delta^{4 a}[30 \%]$} & \multicolumn{2}{|c|}{$\bar{\delta}^{4 \mathrm{~b}}[30 \%]$} & \multicolumn{2}{|c|}{$\bar{\delta}^{\text {all }}[3 \%]$} \\
\hline & & CLK & $\mathrm{CON}$ & CLK & $\mathrm{CON}$ & CLK & $\mathrm{CON}$ & CLK & CON & CLK & CON \\
\hline \multirow{2}{*}{3} & MD & 3.4 & -6.9 & 0.7 & -0.8 & -53.1 & 91.5 & -51.9 & 91.5 & -3.5 & 7.1 \\
\hline & SD & 4 & 2.7 & 1.6 & 0.9 & 2.5 & 30.3 & 2 & 30.3 & 15.9 & 27.1 \\
\hline \multirow{2}{*}{5} & MD & 15.9 & -9.5 & 1.6 & -1.4 & -53.5 & 92.4 & -54.3 & 92.4 & -1.6 & 4.7 \\
\hline & SD & 10.2 & 3.9 & 1.8 & 1.1 & 4.7 & 32.8 & 4.5 & 32.8 & 15.2 & 25.2 \\
\hline \multirow{2}{*}{10} & MD & 2.6 & -4.2 & 0.8 & -0.4 & -28.1 & 13.1 & -21.1 & 13.1 & 0.5 & -0.6 \\
\hline & SD & 2.8 & 0.4 & 1.5 & 0.7 & 18.2 & 16.2 & 22.3 & 16.2 & 8.7 & 5.4 \\
\hline \multirow{2}{*}{15} & MD & 5.9 & -3.3 & 1 & -0.8 & 12.2 & -19.7 & 16.5 & -19.7 & 2.2 & -2.1 \\
\hline & SD & 0.4 & 0.3 & 1.3 & 0.4 & 6.7 & 4.1 & 8.5 & 4.1 & 3.6 & 4 \\
\hline \multirow{2}{*}{20} & MD & 4.8 & -2.8 & 1.1 & -1 & -1.8 & -22.8 & 22.5 & -22.8 & 1.9 & -1.9 \\
\hline & SD & 0.8 & 0.6 & 1.2 & 0.3 & 3.1 & 11.9 & 8.6 & 11.9 & 3.1 & 3.8 \\
\hline
\end{tabular}


Quality Assurance of Three Dimensional Treatment Planning System For External Photon ...

Table 6: MD and SD of difference between measured and calculated PDD using CLK and CON algorithms for $6 \mathrm{MV}, 15 \mathrm{MV}$ for open field size $10 \times 10 \mathrm{~cm}^{2}, 25 \times 25 \mathrm{~cm}^{2} \cdot z_{1}, \zeta_{2}$ and $z_{\text {sum, }}$ represent different regions on the PDD and OAR, and the numbers between the parakeets represents the accepted limit.

\begin{tabular}{|c|c|c|c|c|c|c|c|c|}
\hline \multirow{2}{*}{$\begin{array}{c}\text { Field } \\
\text { size }\left[\mathrm{cm}^{2}\right]\end{array}$} & & & \multicolumn{2}{|c|}{$\delta^{1}[2 \%]$} & \multicolumn{2}{|c|}{$\bar{\delta}^{2}[10 \%]$} & \multicolumn{2}{|c|}{$\bar{\delta}^{\text {sum }}[3 \%]$} \\
\hline & & & $6 \mathrm{MV}$ & $15 \mathrm{MV}$ & $6 \mathrm{MV}$ & $15 \mathrm{MV}$ & $6 \mathrm{MV}$ & $15 \mathrm{MV}$ \\
\hline \multirow{4}{*}{$\begin{array}{c}10 \\
\times \\
10\end{array}$} & \multirow{2}{*}{ CLK } & MD & -0.7 & 0.1 & 0.1 & -1.6 & 0.8 & 1.5 \\
\hline & & SD & 0.7 & 0.3 & 7.4 & 6.3 & 1.7 & 1.5 \\
\hline & \multirow{2}{*}{ CON } & MD & -1.9 & -0.1 & 1.1 & -0.6 & -0.6 & 0.6 \\
\hline & & SD & 1.4 & 0.6 & 7.6 & 6.6 & 1.2 & 0.9 \\
\hline \multirow{4}{*}{$\begin{array}{c}25 \\
\times \\
25\end{array}$} & \multirow{2}{*}{ CLK } & MD & -1.6 & -0.4 & 0.3 & -1.8 & 0.5 & 1.1 \\
\hline & & SD & 1.1 & 0.4 & 0.5 & 6.1 & 1.8 & 1.5 \\
\hline & \multirow{2}{*}{ CON } & MD & -1.3 & -1 & 0.3 & -1.9 & -0.5 & -0.9 \\
\hline & & SD & 1.4 & 0.5 & 0.4 & 6.3 & 0.5 & 0.7 \\
\hline
\end{tabular}

Table 7: MD of ADC for difference between measured dose and calculated dose using CLK, CON in open field sizes $4 \times 4 \mathrm{~cm}^{2}, 10 \times 10 \mathrm{~cm}^{2}, 20 \times 20 \mathrm{~cm}^{2}, 17 \times 7 \mathrm{~cm}^{2}, 12 \times 19 \mathrm{~cm}^{2}$ in SSD technique with using block and without using block [with and without a Tray Factor] for two energy 6MV,15MV with tolerance limit [3\%]

\begin{tabular}{|c|c|c|c|c|c|c|c|}
\hline \multirow{3}{*}{$\begin{array}{c}\text { Field } \\
\text { Size } \text { cm² }^{2}\end{array}$} & \multirow{3}{*}{$\begin{array}{c}\text { Energy } \\
\text { MV }\end{array}$} & \multicolumn{4}{|c|}{ Without Block } & \multirow{2}{*}{\multicolumn{2}{|c|}{ With Block (\%) }} \\
\hline & & \multicolumn{2}{|c|}{$\begin{array}{c}\text { Without Tray } \\
\text { Factor (\%) }\end{array}$} & \multicolumn{2}{|c|}{$\begin{array}{c}\text { With Tray Factor } \\
(\%)\end{array}$} & & \\
\hline & & CLK & CON & CLK & $\mathrm{CON}$ & CLK & CON \\
\hline \multirow{2}{*}{$4 \times 4$} & 6 & -6.3 & -7.1 & -5.1 & -6.8 & -5.1 & -6.8 \\
\hline & 15 & -0.9 & -0.9 & -0.8 & -0.8 & -0.8 & -0.8 \\
\hline \multirow{2}{*}{$10 \times 10$} & 6 & -2 & -2.9 & -2.8 & -2.8 & -1.9 & -2.8 \\
\hline & 15 & 0 & 0 & -0.5 & -0.5 & -0.5 & -0.5 \\
\hline \multirow{2}{*}{$20 \times 20$} & 6 & -1 & -1 & -0.8 & -0.8 & -0.8 & -0.8 \\
\hline & 15 & 0 & 0 & -0.3 & -0.3 & -0.3 & -0.3 \\
\hline \multirow{2}{*}{$17 \times 7$} & 6 & -2.9 & -3.9 & -2.8 & -3.8 & -2.8 & -3.8 \\
\hline & 15 & 0 & $\mathbf{0}$ & -0.5 & -0.5 & -0.5 & -0.5 \\
\hline \multirow{2}{*}{$12 \times 19$} & 6 & -1 & -1 & -0.8 & -0.8 & -0.8 & -0.8 \\
\hline & 15 & 0 & 0 & -0.4 & -0.4 & -0.4 & -0.4 \\
\hline
\end{tabular}

Table 8: MD of ADC for difference between measured dose and calculated dose using CLK, CON in open field sizes $4 \times 4 \mathrm{~cm}^{2}, 10 \times 10 \mathrm{~cm}^{2}, 20 \times 20 \mathrm{~cm}^{2}, 17 \times 7 \mathrm{~cm}^{2}, 12 \times 19 \mathrm{~cm}^{2}$ in SAD technique with using block and without using block [with and without a Tray Factor] for two energy 6MV, 15MV with tolerance limit [3\%]

\begin{tabular}{|c|c|c|c|c|c|c|c|}
\hline \multirow{3}{*}{$\begin{array}{c}\text { Field } \\
\text { Size } \text { cm }^{2}\end{array}$} & \multirow{3}{*}{$\begin{array}{c}\text { Energy } \\
\text { MV }\end{array}$} & \multicolumn{4}{|c|}{ Without Block (\%) } & \multirow{2}{*}{\multicolumn{2}{|c|}{ With Block (\%) }} \\
\hline & & \multicolumn{2}{|c|}{$\begin{array}{c}\text { Without Tray } \\
\text { Factor }\end{array}$} & \multicolumn{2}{|c|}{ With Tray Factor } & & \\
\hline & & CLK & $\mathrm{CON}$ & CLK & CON & CLK & $\mathrm{CON}$ \\
\hline \multirow{2}{*}{$4 \times 4$} & 6 & -11.3 & -12.2 & -11.3 & -12.2 & -10.5 & -12.2 \\
\hline & 15 & -8.7 & -8.7 & -8.4 & -8.4 & -8.4 & -8.4 \\
\hline \multirow{2}{*}{$10 \times 10$} & 6 & -4 & -4 & -3.7 & -3.7 & -3.7 & -3.7 \\
\hline & 15 & -6 & -6 & -6.3 & -6.3 & -6.3 & -5.3 \\
\hline \multirow{2}{*}{$20 \times 20$} & 6 & 0 & 0 & -0.6 & 0.4 & -0.6 & 0.4 \\
\hline & 15 & -4.3 & -4.3 & -4.5 & -3.4 & -3.4 & -3.4 \\
\hline \multirow{2}{*}{$17 \times 7$} & 6 & -3 & -4 & -3.7 & -3.7 & -3.7 & -3.7 \\
\hline & 15 & -6 & -6 & -6.3 & -5.3 & -6.3 & -5.3 \\
\hline \multirow{2}{*}{$12 \times 19$} & 6 & -2.1 & -2.1 & -1.7 & -1.7 & -1.7 & -1.7 \\
\hline & 15 & -5.2 & -5.2 & -5.4 & -5.4 & -5.4 & -4.4 \\
\hline
\end{tabular}

